\title{
Maternal Psychosocial and Environmental Factors Associated With Infant Impaired Development in Sao Paulo, Brazil: A Population-Based Birth Cohort Study
}

\author{
Patricia Constantino de Tella ${ }^{1 *}$, Luis Rohde ${ }^{2}$, Guilherme Polanczyk ${ }^{3}$, Euripedes Miguel ${ }^{3}$, Sandra Grisi ${ }^{4}$, Bacy Fleitlich-Bilyk ${ }^{3}$ and Alexandre \\ Ferraro $^{4}$
}

${ }^{1}$ Dissertation Faculty of Medicine, University of São Paulo, Brazil

${ }^{2}$ Department of Psychiatry and Legal Medicine, Federal University of Rio Grande do Sul, Brazil

${ }^{3}$ Department of Psychiatry, University of São Paulo, Brazil

${ }^{4}$ Department of Pediatrics, University of São Paulo, Brazil

\begin{abstract}
Background: Early life experiences have important consequences on health and human capital throughout life. The development is the result of interaction between the child's biological characteristics and cultural and social factors on which it is inserted. Biological factors that cause developmental delay associated with environmental factors increase the chance of the infant having an inappropriate development. This shows the importance of studies assessing factors related to child development.
\end{abstract}

Objective: The aim was to characterize the neurological development of children 6-8 months ago through the Bayley scale in a population-based sample, then estimate the prevalence of delay and identifying psychosocial and environmental risk factors.

Method: A longitudinal epidemiological study of birth cohort study in a group of 368 infants and their mothers. Two moments of assessment were considered: $a$ ) at the beginning of the third trimester of gestation and $b$ ) when the infants were 6-8 months of age. The study aims to examine the neurological development of the children considered for the study through the Bayley scale, to estimate the prevalence of delay in a population-based sample and, finally, to identifying maternal psychosocial and environmental risk factors.

Results: Indicated that maternal stress factors (i.e. anxiety and substance disorder during pregnancy, lower maternal schooling and economic class) were associated with lower cognitive development in infants.

Conclusion: This study shows the importance of screening to identify possible developmental delays, for subsequent intervention programs to prevent or minimize future hazards and allow the child to develop to their full potential.

Keywords: Development; Risk factors; Infants; Bayley; Development delay

\section{Introduction}

It has been shown that early life experiences have important consequences on health and human capital throughout life [1,2]. Developmental impairment, for instance, affects $40 \%$ of children living in poverty, with long-term consequences that perpetuate the cycle of poverty [3]. Many children arrive at school age not ready to start studying [4]. Emerging societies have recently accomplished significant macro-economic improvements. However, huge persistent gaps in cognitive abilities among and within societies challenge farther progress [5].

Some predictors of developmental delay are well established: socioeconomic and environmental conditions, birth outcomes such as nutrition, gestational age and hypoxia, parenting skills and maternal mental health [6-9].

Nevertheless it will clear need of more studies. Analysis on maternal mental health has been concentrated mainly on depression, especially post-partum depression $[10,11]$. Fewer frequent studies that include other pre-partum mental disorders [12-15], as well as important environmental stressors, as violence. Yet these conditions are highly prevalent in developing countries and in deprived areas of wealthier nations [16-24]. In addition to this, most evidence comes from studies that were carried in clinical settings, lacking data on populationbased samples [12]; developmental assessment in epidemiological studies are seldom done through more sophisticated tests that requires trained professionals $[3,8]$; finally the identification of effect-modifiers (interaction) in these association has been acknowledge as necessary [25].

Most studies on delayed psychomotor child development are focused on biological high-risk groups: premature and low-weight. Lacking studies, that use measures were more complex development, as well as the results of the Bayley Scale development tool as gold standard. The identification of psychosocial and environmental factors, not just biological, facilitates early identification of the vulnerable groups that can benefit from interventions before installing problem. The present study aims to characterize the cognitive, language and motor

*Corresponding author: Patricia Constantino de Tella, Psychologist, Dissertation Faculty of Medicine, University of São Paulo, Brazil, Tel: +1-347-561-1195; E-mail: patriciatella@usp.br

Received November 27, 2015; Accepted February 01, 2016; Published February 07, 2016

Citation: de Tella PC, Rohde L, Polanczyk G, Miguel E, Grisi S, et al. (2016) Maternal Psychosocial and Environmental Factors Associated With Infant Impaired Development in Sao Paulo, Brazil: A Population-Based Birth Cohort Study. J Psychiatry 19: 351 doi:10.4172/2378-5756.1000351

Copyright: @ 2016 de Tella PC, et al. This is an open-access article distributed under the terms of the Creative Commons Attribution License, which permits unrestricted use, distribution, and reproduction in any medium, provided the original author and source are credited 
development in a cohort of 6-month-old infants living in an area of high social vulnerability; to estimate the associated maternal psychosocial and environmental predictors of lower development scores; to identify a possible variable that modifies these associations.

\section{Methodology}

\section{Subjective}

The present work is a longitudinal epidemiological study, a birth cohort, with two moments of assessments: the first in the beginning of the third trimester of gestation and the second when the infant was 6-8 months of age. The population from which the sample was extracted was women who attend primary health facilities in the west region of the city of Sao Paulo, Brazil. This is a deprived area, in the outskirts of a big metropolis. Thanks to the Family Health Strategy - upon which Brazilian national health system is structured coverage rates are good in this area, with monthly home visiting by lay health workers who identify pregnant women and link them to the pre-natal care visits [24]. Field researchers were communicated when a new pregnant woman was eligible to be enrolled. The present study is made of a sub-sample that derives from birth cohort of 900 pregnant women that aims to study developmental psychiatry. Statistical procedures were used to minimize potential selection bias. A convenience sample of 368 newborns was then followed up during the first semester of their lives. Since this sampling procedure could have introduced an important selection bias, a detail comparison was conducted between the followed up and the non-followed up samples. Analysis took into account any difference that was found, pondering for them. The statistical power of this sample size, assuming a probability of occurring type I error of 5\%; a incidence rate of developmental delay among non-depressed mothers of $10 \%$ and among depressed mothers of $30 \%$; a frequency of depression of $20 \%$, the statistical power of this sample size would be $80 \%$.

Inclusion criteria were to live in the adscript territory and to be between the $26^{\text {th }}$ and the $34^{\text {th }}$ week of gestation. Children who were born with any congenital syndrome associated with developmental impairment as well as twins were not included in the analysis.

\section{Instruments}

Outcome assessment tool was the Bayley Scale of Infant Development III, it is validated version for the Brazilian context [25]. The Bayley III is among the best existing ranges in the assessment area of child development, as 'gold standard' by several authors. It comprises 326 items divided in five subscales: cognitive scale, motor scale (fine and gross motor skills) and language scale (expressive and receptive). It is a complete and detailed assessment of neurodevelopmental, both for assessing the general population and to evaluate risk groups (premature babies, for example), as well as for the evaluation of specific developmental disorders such as, for example, autism.

The following domains were tested: motor, language and cognitive development. It took from $1 / 2 \mathrm{~h}$ to $1 \mathrm{~h}$ to complete this assessment that was conducted mainly in the primary health facility. The adequacy of the environment was essential in the decision of where to do it, also thanks to the nature of the other assessments that were done (domestic violence and mental disorders).

- Independent variables were: socio economic status, measured through paternal occupation, maternal schooling and economic class; maternal age (adolescent mother); maternal migration (not being born in Sao Paulo); unwanted pregnancy; being a primipara mother; smoking during gestation; birth conditions extracted from medical records, including birth weight, length, gestational age; domestic violence against women and maternal mental health.

- Trained psychologists collected all information. Domestic violence against women was measured according to the WHO Domestic Violence Questionnaire [26]. Mental health disorders were measured according to the Mini International Neuropsychiatric Interview (MINI), a short structured diagnostic interview, which priories current disorders [27]. Both exposure measurements had been previously adapted to the Brazilian population $[19,28]$. Physical, psychological and sexual violence were pooled in one variable. It was considered positive a reported episode of violence in the last 12 months. Metal disorders were pooled in the following groups: "mood disorder" (current hypomanic episode, current manic episode, current dysthymic disorder, current major depression), "anxiety" (current panic disorder without agoraphobia, current panic disorder with agoraphobia, social phobia, post-traumatic stress disorder, general anxiety disorder), "substance dependence" (alcohol and illicit drugs), "anti-social personality disorder", "psychotic disorder" and "risk of suicide" (moderate and high risks pooled together).

\section{Statistical analysis}

Analysis was performed by using the $\operatorname{STATA}^{\circ} 12$ software. Initially a descriptive analysis was conducted, reporting the frequencies of the collected categorical variables with their $95 \%$ confidence interval and median and interquartile interval of the continuous variables. Afterwards the association between every independent variable and the outcome was tested through bivariate and multivariate Poisson regression models. It has been suggested that Poisson regression is a good way of estimating relative risks in cohort studies. For this purpose cognitive, motor and language developments were transformed in binary variables ("low development") defined by being under the 1st quartile of the distribution. To deal with missing data we chose instead to perform in all models inverse probability weighting. The null hypothesis was rejected at a probability level lower than $5 \%$. The association between exposure and outcome can be modulated by a third variable. This variable may act by modifying the association, which is called interaction. The presence of interaction was studied by assessing uniformity of the stratum-specific effect estimates through chi-square test for heterogeneity. Given its low statistical power, the null hypothesis in this test was rejected at a probability level of lower than $10 \%$.

\section{Ethical considerations}

All candidate mothers were invited to take part in the study by a free informed consent, presented by a professional ready to identify cases with reading /or comprehension problems. Data from hospital charts were used only after mothers' consent. Regarding the survey about violence, the guidelines of the document from WHO "Putting Women First: ethical and safety recommendations for research on domestic violence against women" were used [20]. The autonomy of the subject was respected when mental disorders or violence were identified. Field researchers tried to empower them suggesting what to do in these cases. If any greater hazard (to the mother or to the child) was acknowledged the family health team was also contacted the local ethics in research committee approved the research protocol.

\section{Results}

We analyzed the cognitive, language and motor development of 368 infants between 6 and 8 months of age. Extremely low/borderline 
development was identified $1.6 / 9.2 \%$ the motor domain, $1.4 / 1.6 \%$ the cognition domain and $1.1 / 7.1 \%$ the language domain. In total, infants having developmental delays were $15.4 \%$. Table 1 shows the differences between the followed up mothers and the non-followed up mothers. It was found that domestic violence, substance dependence, disorders, psychotic, anxiety, social -personality disorders and suicide risk during pregnancy were similar present equally the recruited sample and the studied one. Mood disorders, however, were more frequent in the beginning. Socio-demographic profile and gestational variables did not differ between the survey and the birth cohort sample risk factors studied compared with the group and the group followed with loss of follow-up, it was found that there was no significant difference between samples (Table 2). Even if $9.24 \%$ of the infants had delayed motor development at 6 months, children who had less scored both stress factors during pregnancy. The unwanted pregnancy showed a tendency to association with delayed motor development at 6 months.

Babies born small for gestational age tend to more likely to have delayed motor development when adjusted to multivariate factors. We also observed that the increasingly month old babies increased significantly the chance to have delayed motor development, in bivariate analysis the risk is $57 \%$ and when adjusted for confounding factors the probability was $45 \%$. Evince that small for gestational ages are associated with language delay, even after adjustment for the multivariate model. And the older the child is also linked to language development delay, even after adjusting for confounding factors (Table 3). Small babies for gestational age have a tendency to associate with delayed cognitive development, but after adjustment that the association of cognitive delay is statistically significant. And breastfeeding until 6 months has a tendency to protective factors, if children breastfed until 6 months showed a trend associated with increasing the scores of cognitive development (Table 3).

Demonstrate that, the mood disorder and mental violence during both during pregnancy has a tendency to be predictors delay in language development. And after the multivariate analysis the mood disorder during pregnancy continued with the trend for the association in the delay in language development. Anxiety disorder, antisocial personality disorder and sexual violence were associated with delayed cognitive development, even after adjusting for multivariate models. Dependence on substances during pregnancy is also associated with delayed cognitive development, but was not associated after adjustments for confounders.

We've found on Table 3, that the economy class is statistically associated with decreased scores in language development at 6 months, even after adjustment for confounding factors. And the mother of children who smoked in pregnancy had a trend likely to score lower language development score in the bi-variate analysis, but after multivariate analysis, smoking during pregnancy becomes statistically

\begin{tabular}{|c|c|c|c|}
\hline & Cohort & Sub Sample & \multirow{2}{*}{$\boldsymbol{p}$} \\
\cline { 2 - 4 } & $\%($ IC 95\%) & $\%($ IC 95\%) & \\
\hline Domestic Violence & $28.82(24.90 / 32.73)$ & $22.88(18.48 / 27.28)$ & 0.051 \\
\hline Mood Disorders & $32.44(28.42 / 36.46)$ & $25.61(21.12 / 30.10)$ & 0.028 \\
\hline Anxious Disorders & $17.55(14.28 / 20.82)$ & $14.67(11.04 / 18.3)$ & 0.252 \\
\hline Drugs Abuses & $4.96(3.09 / 6.82)$ & $2.98(01.24 / 4.73)$ & 0.146 \\
\hline Psychotic Disorders & $4.19(2.47 / 5.92)$ & $2.71(01.04 / 4.38)$ & 0.242 \\
\hline Personality Disordes & $2.09(0.86 / 3.33)$ & $2.17(0.67-03.67)$ & 0.939 \\
\hline Risc Suicide & $6.67(4.53 / 8.82)$ & $5.16(2.89 / 07.43)$ & 0.350 \\
\hline
\end{tabular}

Table 1: Distribution of maternal stress factors during pregnancy in the initial cohort in the sub-sample analyzed at 6 months in infants. São Paulo 2014.

\begin{tabular}{|c|c|c|c|c|}
\hline & & $\begin{array}{l}\text { Sub-Sample } \\
\qquad(n=365) \\
\%(\text { IC } 95 \%)\end{array}$ & $\begin{array}{c}\begin{array}{c}\text { Inicial Sample } \\
(n=524)\end{array} \\
\%\end{array}$ & $p$ \\
\hline $\begin{array}{l}\text { Entrepreneur } \\
\text { Father }\end{array}$ & $\begin{array}{l}\text { Non manual. } \\
\text { qualified } \\
\text { Manual } \\
\text { qualified } \\
\text { Manual. non- } \\
\text { qualified }\end{array}$ & $\begin{array}{c}16.91(12.92 \\
-20.90) \\
18.37(14.25- \\
22.49) \\
64.72(59.64- \\
69.81) \\
\end{array}$ & $\begin{array}{l}17.51(14.15-20.86) \\
17.91(14.52-21.29) \\
64.59(60.37-68.81)\end{array}$ & 0.995 \\
\hline Live with Father & Y & $\begin{array}{c}72.40(67.80- \\
77.00)\end{array}$ & 74.13(70.34-77.91) & 0.929 \\
\hline Economic Status & $\begin{array}{c}A+B \\
C \\
D+E\end{array}$ & $\begin{array}{c}17.11(13.25- \\
20.98) \\
66.84(62.01- \\
71.68)\end{array}$ & $\begin{array}{l}65.64(61.56-69.72) \\
16.79(13.58-20.00)\end{array}$ & \\
\hline $\begin{array}{l}\text { Maternal } \\
\text { Education }\end{array}$ & $\begin{array}{c}<8 \text { anos } \\
8-10 \text { anos } \\
11 \text { ou }+ \text { anos } \\
\end{array}$ & $\begin{array}{c}17.93(13.99- \\
21.87)\end{array}$ & $19.69(16.27-23.11)$ & 0.801 \\
\hline Adolescent & Y & $\begin{array}{c}24.72(20.29- \\
29.15)\end{array}$ & $20.61(17.13-24.08)$ & 0.146 \\
\hline Not born in SP & Y & $\begin{array}{c}41.64(36.56- \\
46.72)\end{array}$ & $45.10(40.81-49.39)$ & 0.307 \\
\hline Primiparous & $\mathrm{Y}$ & $\begin{array}{c}49.86(44.72- \\
55.00) \\
\end{array}$ & $46.18(41.90-50.46)$ & 0.279 \\
\hline $\begin{array}{l}\text { Not desired } \\
\text { gestation }\end{array}$ & Y & $\begin{array}{c}18.80(14.78- \\
22.81)\end{array}$ & $21.07(17.56-24.58)$ & 0.406 \\
\hline Smoke & $\mathrm{Y}$ & $\begin{array}{c}13.85(10.31- \\
17.40) \\
\end{array}$ & $18.58(15.23-21.93)$ & 0.062 \\
\hline Genre Infant & $\begin{array}{c}\text { Male } \\
\text { Female }\end{array}$ & $\begin{array}{c}47.39(42.25- \\
52.54) \\
\\
52.60(47.45- \\
57.74) \\
\end{array}$ & $\begin{array}{l}48.43(43.60-53.26) \\
51.56(46.74-56.39)\end{array}$ & 0.772 \\
\hline
\end{tabular}

Economy class: A-B reference; C first extract; D-E second layer (risk of change stratum)

Maternal education: Some Fundamental first layer; Full average second layer Completed high or more. third layer (risk of change stratum)

$95 \% \mathrm{Cl}=95 \%$ confidence interval

* Risk of being in the lowest quartile of motor development score in relation to the sample

** Model adjusted for the variables with $p<0.20$

Table 2: Socio-demographic characterization and gestational risk factors of the sample and comparison between the group and the group followed with loss following a birth cohort in the city of SP, 2014.

significant for the child has developmental delay language to 6 months. Economy class and maternal education are associated with delayed cognitive development in infants at 6 months, but multivariate model shows the contribution specifies that variable when put together, does not appear unique. And smoking during pregnancy had a tendency to decrease in scores on cognitive development in Bayley Scale applied to six months.

Figure 1 illustrates the change of association among exposures (anxiety, economic class and maternal education) and lower cognitive development when a third variable is present. The negative affect of anxiety on cognitive development in infants is visible in the infants of mothers who had higher gestational weight gain. Being from a family of low socioeconomic class greatly increases the risk of lower cognitive development, but this risk is virtually nullified if the mother is breastfeeding in the sixth month of gestation. Similarly, the deleterious effect of economy class is much more evident on premature babies born at term. And finally, low maternal education is associated with lower 
Citation: de Tella PC, Rohde L, Polanczyk G, Miguel E, Grisi S, et al. (2016) Maternal Psychosocial and Environmental Factors Associated With Infant Impaired Development in Sao Paulo, Brazil: A Population-Based Birth Cohort Study. J Psychiatry 19: 351 doi:10.4172/2378-5756.1000351

Page 4 of 6

\begin{tabular}{|c|c|c|c|c|c|c|}
\hline \multirow{2}{*}{$\begin{array}{c}\text { Predictors } \\
\text { Factors }\end{array}$} & \multicolumn{2}{|c|}{ Motor } & \multicolumn{2}{|c|}{ Language } & \multicolumn{2}{|c|}{ Cognition } \\
\hline & Relative Risk & IC $95 \%$ & Relative Risk & IC $95 \%$ & Relative Risk & IC $95 \%$ \\
\hline Mood Disorders & 0.89 & $0.58-1.36$ & $1.39^{*}$ & $0.96-2.02$ & 1.16 & $0.75-1.78$ \\
\hline Anxious Disorders & 1.03 & $0.63-1.69$ & 1.13 & $0.70-1.81$ & $1.61^{\star}$ & $1.03-2.53$ \\
\hline Drug Abuses & 0.79 & $0.22-2.89$ & 1.45 & $0.59-3.57$ & $2.15^{\star}$ & $1.04-4.44$ \\
\hline Risk of Suicide & 0.52 & $0.18-1.54$ & 1.30 & $0.64-2.66$ & 1.39 & $0.68-2.83$ \\
\hline Personality Disorders & 0.74 & $0.20-2.70$ & 1.15 & $0.42-3.16$ & $2.82^{*}$ & $1.65-4.80$ \\
\hline Psychotic Disorders & 0.86 & $0.25-2.98$ & 0.37 & $0.06-2.47$ & 0.42 & $0.06-2.81$ \\
\hline Physical Violence & 0.75 & $0.38-1.49$ & 1.25 & $0.74-2.13$ & 1.34 & $0.76-2.34$ \\
\hline Psychic Violence & 0.92 & $0.59-1.44$ & $1.39^{*}$ & $0.95-2.05$ & 1.31 & $0.85-2.04$ \\
\hline Sexual Violence & 0.91 & $0.27-3.09$ & 0.54 & $0.09-3.23$ & $2.35^{*}$ & $1.24-4.44$ \\
\hline Economic Status & 1.14 & $0.85-1.53$ & $1.42^{*}$ & $1.07-1.90$ & 1.41 & $1.03-1.91$ \\
\hline Maternal Education & 0.84 & $0.67-1.06$ & 0.91 & $0.72-1.15$ & 0.74 & $0.57-0.96$ \\
\hline Adolescent & 0.80 & $0.51-1.24$ & 0.91 & $0.60-1.39$ & 0.79 & $0.46-1.33$ \\
\hline Migration & 1.01 & $0.71-1.43$ & 0.83 & $0.58-1.19$ & 0.85 & $0.58-1.27$ \\
\hline Primipara & 0.96 & $0.68-1.37$ & 1.23 & $0.86-1.76$ & 0.88 & $0.60-1.30$ \\
\hline Unwanted Pregnancy & $0.65^{\star}$ & $0.38-1.11$ & 1.07 & $0.68-1.68$ & 1.24 & $0.79-1.93$ \\
\hline Smoking & 0.97 & $0.59-1.61$ & $1.49^{*}$ & $0.97-2.28$ & 1.45 & $0.90-2.35$ \\
\hline Alcohol intake & 0.89 & $0.47-1.67$ & 0.85 & $0.43-1.65$ & 1.15 & $0.62-2.12$ \\
\hline Prematurity & 1.37 & $0.79-2.39$ & $1.09^{*}$ & $0.57-2.08$ & 0.91 & $0.41-2.02$ \\
\hline IUGR (quartis) & $1.15^{\star}$ & $0.98-1.36$ & 1.22 & $1.04-1.42$ & 1.18 & $0.99-1.40$ \\
\hline Non-breastfeeding at $6 \mathrm{~m}$ & 1.22 & $0.84-1.76$ & 1.06 & $0.73-1.55$ & 1.41 & $0.94-2.11$ \\
\hline Gender (female) & 0.83 & $0.59-1.19$ & 0.87 & $0.61-1.25$ & 0.96 & $0.65-1.41$ \\
\hline Age (months) & 1.57 & $1.18-2.08$ & 1.48 & $1.11-1.97$ & 1.12 & $0.79-1.57$ \\
\hline
\end{tabular}

${ }^{*} p<0.10 ;{ }^{* *} p<0.05$

$95 \%$ IC $=95 \%$ confidence interval

Risk of being in the lowest quartile of motor development score in relation to the sample

${ }^{* * *}$ Model adjusted for the variables with $p<0.20$ is present.

".*t.The lower risk than 1 implies a reduction of disease exposure

IGR = increasing quartiles of intrauterine growth retardation

Table 3: Association of gestational factors and infant birth to the child development at 6 months, bivariate analysis
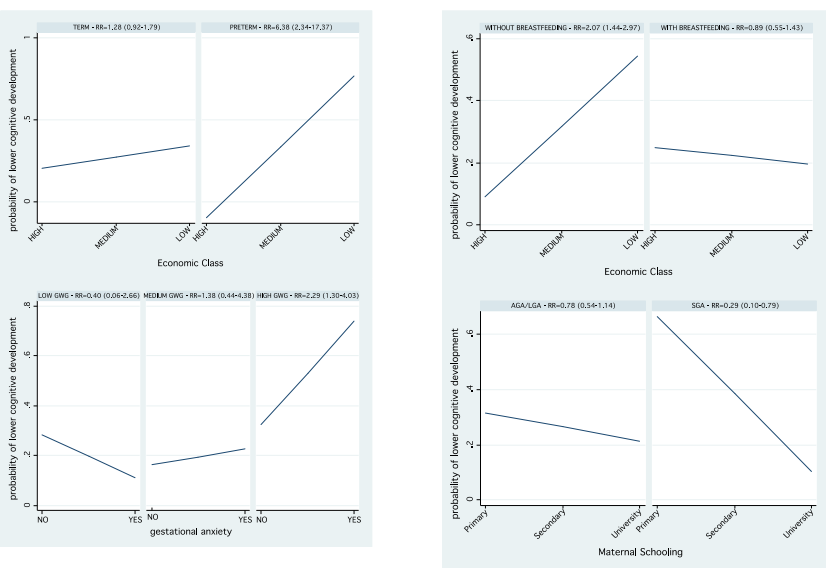

$\mathrm{RR}=$ relative risk with $95 \%$ confidence interval; GWG= tertiles of gestational weight gain; AGA/LGA= adequate and large for gestational age; SGA= small for gestational age

Figure 1: Interaction in the association between exposures and cognitive development.

cognitive development, but excessively in infants that born small for gestational age.

\section{Discussion}

We found low frequencies of developmental delay at 6 months of age in this deprived neighbourhood birth cohort. Maternal psychosocial stressors, as mental disorders and violence, however, were highly prevalent. Better economic class and maternal education predicted higher language and cognitive scores. Maternal mood disorder, substance dependence and risk of suicide during pregnancy were associated with lower language and cognitive scores. Independent associations of maternal mood disorder and substance dependence were found with infant's language and cognition. One of the strongest points of this work is assessing in the field infant development through a well-established and complex toll, at a population level. This point becomes even stronger when we consider the high social vulnerability under which the studied sample lived. The research team had to surpass physical and environmental challenges, as criminality, to have access to these women and their children. In this sense, local health workers were essential guides and advisers. Mental disorders are strongly linked to financial difficulties and with experience of violence. It is known that these individuals I tend to lack self-care and therefore to have less appetite, less access to prenatal care and greater alcohol, tobacco and illicit drug abuse [21]. Preterm birth and low birth weight are, consequently, more frequent among these women [22]. Lower infant scores can explain these mechanisms; nevertheless the association remained after adjustments for SES factors, maternal characteristics and birth conditions.

Anxiety disorder in pregnancy was associated with deficits in cognitive development, even after adjusting for confounding factors. Going through the possible modulating effects on this relationship we found that gestational weight gain modified this association. Anxiety tends to an increase or loss of abrupt weight due to the symptoms of the disorder and also due to the increase in cortisol hormones index and adrenaline that can cause fat gain. The Institute of Medicine (US) 
and the National Council Research (US) in 2009 analysed women in pre-pregnancy with a body mass index (BMI) and during pregnancy with weight gain, the analysis showed that among women with a high pre-pregnancy BMI and weight gain were associated with increased odds of ADHD in children and between lean women with weight loss during pregnancy also had higher chances of having a child who could develop ADHD compare to those who did not lose weight during pregnancy. The mechanisms for these effects are unknown, although the authors speculate on the possibility of transfer of neurotoxin from maternal adipose tissue for the developing foetal brain. The human brain develops rapidly during pregnancy and in the postnatal period, it is possible that the maternal body fat stores and gestational weight gain can influence the central nervous system of the foetus, resulting behaviour disorders as attention deficit hyperactivity disorder (ADHD) [25].

It has been reported elsewhere an association between cognition and maternal education. There is some evidence that suggests that mothers who have studied more have a better physical and temporal environmental organization, more opportunities to vary daily stimulation with different availability of tools and games more suitable for their toddlers and greater emotional and verbal link [23]. However, less schooling is an important SES marker. Its association with lower developmental scores may explain the fact that low SES mothers have a greater risk to bear premature or small for gestation age babies [24]. Social class is a factor linked to maternal education, a factor that was associated with cognitive development and a predictive factor was the gestational gain related to maternal education, related to lack of nutrition and prenatal care quality. In this study, it was found that the mother this study time with the development of the child to 6 months. This relationship can be associated with a qualified daily stimulation with higher maternal repertoire and availability across the baby's needs $[28,29]$. Social class is a risk factor that generates build-up to other factors such as dangerous in housing, lack of basic resources hygiene, stimulation necessary to develop new skills, as well as association with parental education, lack of nutritional supplies needed to maturation, child growth and prematurity. The development of genetic inheritance also depends on the opportunities offered by the environment [7,30,31]. These deleterious effects of economic class explain the association found among premature babies.

However, we also found that breastfeeding until 6 months of age is associated with a better performance, almost "correcting" the deficit caused by socioeconomic status. Children from lower social classes became to show better cognitive performance scores than those who were not breastfed, or breast-feeding corrected the problem of poverty in cognition. In studies have found that breastfeeding in the first quarter is associated with better development of babies, these effects reflect six months in tests that assess the psychomotor development [32-34]. Studies show that during breastfeeding, the mother responds better to the needs of the child, spend more time interacting with the child or stimulating activities than mothers who do not breastfeed. In addition, breastfeeding helps to better oral motor development by suction [35].

This study is critical to literature and community, on the characteristics of child development, establishing parameters for comparison and prevention in developmental delay, are few studies on psychosocial and environmental effects on the development of the first years of life in Brazil. Therefore, prevention program to the families of high vulnerability are important on early childhood, there is evidence that the early intervention are important of child's future life [36-39].

\section{Conclusion}

We conclude that anxiety and substance disorder during pregnancy, together with lower maternal schooling and economic class are predictors of lower cognitive development in infants aging 6-8 months. These associations are highly modulated by other factors, such as gestational weight gain and breastfeeding, potentially modified behaviours. Health workers should be trained to identify these conditions and, in this way, prevent future developmental delays.

\section{Limitation}

Able to maintain the link with families, often vulnerable, was essential for the research because, well, it was possible to pursue all established steps and get trustworthy and reliable information, and assure assessment of child development through a well-established approach. The research team had to overcome physical and environmental challenges attributable to the difficulty of access to community and understanding, by the residents of the importance of the study to the population. In addition, we had to face risks, because the high level of community crime, and overcome the difficulty of access women and children of the research, that often required home visits to the continuation of the project in the predetermined time. This point becomes even stronger since researchers should make sure that these variables were in favor of a good application and authenticity of the results and required maximum attention to the preservation of confidentiality of information.

\section{Conflict of Interest and Funding}

Institution at any time receives payment or support in kind for any aspect of the submitted work: Money paid to your institution, this means money that your institution received for your efforts on this study. Name of entity making grant/payment: Conselho Nacional de Desenvolvimento Científico e Tecnológico - "National Counsel of Technological and Scientific Development.

\section{References}

1. Victora CG, Adair L, Fall C, Hallal PC, Martorell R, et al. (2008) Maternal and Child Undernutrition Study Group. Maternal and child undernutrition: consequences for adult health and human capital. Lancet 371: 340-357.

2. Adair LS, Fall CH, Osmond C, Stein AD, Martorell R, et al. (2013) Associations of linear growth and relative weight gain during early life with adult health and human capital in countries of low and middle income: findings from five birth cohort studies. Lancet 382: 525-534.

3. Halpern R, Barros FC, Horta BL, Victora CG (1996) [Developmental status at 12 months of age in a cohort of children in southern Brazil: differences according birthweight and family income] Cad Saude Publica 12 Suppl 1: 73-78.

4. Steinmetz N (2010) The development of children and the health of societies Paediatr Child Health 15: 11-12.

5. Organisation for Economic Co-operation and Development (2013) PISA 2012 Results: Creative Problem Solving.

6. Lovejoy MC, Graczyk PA, O'Hare E, Neuman G (2000) Maternal depression and parenting behavior: a meta-analytic review. Clin Psychol Rev 20: 561-592.

7. Halpern R, Giugliani ER, Victora CG, Barros FC, Horta BL (2000) [Risk factors for suspicion of developmental delays at 12 months of age] J Pediatr (Rio J) 76: $421-428$

8. Morris SS, Grantham-McGregor SM, Lira PI, Assunção AM, Ashworth A (1999) Effect of breastfeeding and morbidity on the development of low birthweight term babies in Brazil. Acta Paediatr 88: 1101-1106.

9. Kelly RH, Danielsen BH, Golding JM, Anders TF, Gilbert WM, et al. (1999) 
Citation: de Tella PC, Rohde L, Polanczyk G, Miguel E, Grisi S, et al. (2016) Maternal Psychosocial and Environmental Factors Associated With Infant Impaired Development in Sao Paulo, Brazil: A Population-Based Birth Cohort Study. J Psychiatry 19: 351 doi:10.4172/2378-5756.1000351

Adequacy of prenatal care among women with psychiatric diagnoses giving birth in California in 1994 and 1995. Psychiatr Serv 50: 1584-1590.

10. Cummings EM, Davies PT (1994) Maternal depression and child development. J Child Psychol Psychiatry 35: 73-112.

11. Hay DF, Pawlby S, Sharp D, Asten P, Mills A, et al. (2001) Intellectual problems shown by 11-year-old children whose mothers had postnatal depression. J Child Psychol Psychiatry 42: 871-889.

12. Kim HG, Mandell M, Crandall C, Kuskowski MA, Dieperink B, et al. (2006) Antenatal psychiatric illness and adequacy of prenatal care in an ethnically diverse inner-city obstetric population. Arch Womens Ment Health 9: 103-107.

13. Bennett HA, Einarson A, Taddio A, Koren G, Einarson TR (2004) Prevalence of depression during pregnancy: systematic review. Obstet Gynecol 103: 698709 .

14. Victora CG, Barreto ML, do Carmo Leal M, Monteiro CA, Schmidt MI, et al. (2011) Health conditions and health-policy innovations in Brazil: the way forward. Lancet 377: 2042-2053.

15. Bayley N (1993) Bayley scales of infant development (2nd Edn), San Antonio.

16. World Health Organization (2005) Multi-country Study on Women's Health and Domestic Violence against Women.

17. Sheehan DV, Lecrubier Y, Sheehan KH, Amorim P, Janavs J, et al. (1998) The Mini-International Neuropsychiatric Interview (M.I.N.I.): the development and validation of a structured diagnostic psychiatric interview for DSM-IV and ICD10. J Clin Psychiatry 59: 22-33.

18. Schraiber LB, Latorre Mdo R, Franca I Jr, Segri NJ, D'Oliveira AF. (2010) Validity of the WHO VAW study instrument for estimating gender-based violence against women. Rev Saude Publica 44: 658-666.

19. Amorim P (2000) Mini International Neuropsychiatric Interview (MINI) validação de entrevista breve para diagnóstico de transtornos mentais. Rev Bras Psiquiatr 22: 106-115.

20. World Health Organization (2001) Putting Women First: Ethical and Safety Recommendations for Research on Domestic Violence Against Women.

21. Pereira PK, Lovisi GM (2008) Prevalência da depressão gestacional e fatores associados. Rev psiquiatr clín 35.

22. Liaw FR, Brooks-Gunn J (1993) Patterns of low-birth-weight children's cognitive development. Developmental Psychology 29: 1024-1035.

23. Rodriguez A, Miettunen J, Henriksen TB, Olsen J, Obel C, et al. (2008) Maternal adiposity prior to pregnancy is associated with $A D H D$ symptoms in offspring: evidence from three prospective pregnancy cohorts. Int J Obes (Lond) 32: 550-557.
24. Vranjac A (2003) Nicotine: Drug Universal. Epidemiological Surveillance Center.

25. Andrade SA, Santos DN, Bastos AC, Pedromônico MR, de Almeida-Filho $\mathrm{N}$, et al. (2005) [Family environment and child's cognitive development: an epidemiological approach]. Rev Saude Publica 39: 606-611.

26. Grantham-McGregor SM, Lira PI, Ashworth A, Morris SS, Assunçao AM (1998) The development of low birth weight term infants and the effects of the environment in northeast Brazil. J Pediatr 132: 661-666.

27. Entringer S, Buss C, Wadhwa PD (2010) Prenatal stress and developmental programming of human health and disease risk: concepts and integration of empirical findings. Curr Opin Endocrinol Diabetes Obes 17: 507-166.

28. Carvalho P, Pereira P, Frias PG (2007) Risk factors for neonatal mortality in hospital coort of live births. Epidemiol Serv Saúde 16: 185-194.

29. Biscegli TS, Polis LB, Santos LM, Vicentin M (2007) Avaliação do estado nutricional e do desenvolvimento neuropsicomotor em crianças frequentadoras de creche. Rev Paul Pediatr 25.

30. Halpern R, Barros FC, Horta BL, Victora CG (1996) Desenvolvimento neuropsicomotor aos 12 meses de idade em uma coorte de base populacional no Sul do Brasil: diferenciais conforme peso ao nascer e renda familiar. Cad. Saúde Pública 12: 73-78.

31. Halpern R, Giugliani ERJ, Victora CG, Barros FC, Horta BL (2000) Fatores de risco para suspeita de atraso no desenvolvimento neuropsicomotor aos 12 meses de vida. Rev Chil Pediatr 73: 529-539.

32. Grantham-McGregor S (1995) A review of studies of the effect of severe malnutrition on mental development. J Nutr 125: 2233S-2238S.

33. Levitsky DA, Strupp BJ (1995) Malnutrition and the brain: changing concepts, changing concerns. J Nutr 125: 2212S-2220S.

34. Wachs TD (1995) Relation of mild-to-moderate malnutrition to human development: correlational studies. J Nutr 125: 2245S-2254S.

35. Straub WJ (1961) Malfunction of the tongue. Am J Orthodon 47: 596-617.

36. Dworkin PH (1989) British and American recommendations for developmental monitoring: the role of surveillance. Pediatrics 84: 1000-1010.

37. Pinto EB (2009) O desenvolvimento do comportamento do bebê prematuro no primeiro ano de vida. Psicol Reflex Crit 22.

38. Pinto I, Padovani F, Linhares MB (2009) Ansiedade e Depressão Materna Relatos sobre o Bebê Prematuro. Psicologia: Teoria e Pesquisa 25: 075-083.

39. Valman HB (1980) Development surveillance at 6 weeks. Br Med J 280: 1000 1002. 